40

$x$

LES

\title{
BASES PHILOSOPHIQUES
}

$\mathrm{DU}$

DROIT INTERNATIONAL PRIVÉ

PAR

HECTOR LAM BRECHTS

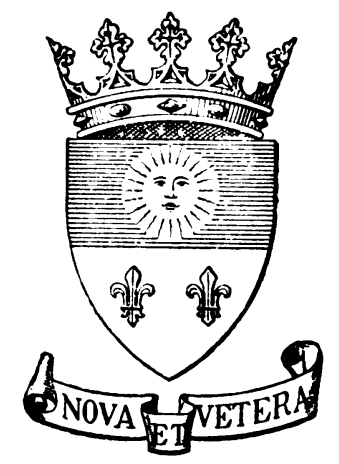

Extrait de la REVUE NEO-SCOLASTIQUE, 1895.

LOUVAIN

ÉCOLE SAINT THOMAS

INSTITUT SUPÉRIEUR DE PHILOSOPHIE DE L'UNIVERSITÉ

1, RUE Des flamands, 1

$\overline{1895}$ 